\title{
From Moral Ambivalence to Differential Congruence: Understanding Transnational Sexuality Using Cultural Schemas ${ }^{1}$
}

Apoorva Ghosh, University of California, Irvine ${ }^{2}$

\begin{abstract}
Through in-depth interviews, this study aimed to show how lesbians and gay men in India may construct their sexuality as a result of being globally connected through accessing "transnational pathways," such as the global mass media, diasporic experiences, and transnational workplaces. This study indicates that these pathways aid in the interaction between externally derived sexual schemas and pre-existing sexual schemas, which may in turn lead to a configuration of "differential congruence” whereby competing sexual schemas may coexist rather than fuse or replace each other in an individual's life, albeit in different spheres.
\end{abstract}

\section{Keywords}

cultural schemas, transnational sexualities, gay men, lesbians, India

\footnotetext{
${ }^{1}$ Cite this article as: Ghosh, Apoorva (2019). "From moral ambivalence to differential congruence: Understanding transnational sexuality using cultural schemas.” Sexualities, online first: https://doi.org/10.1177/1363460719850022

${ }^{2}$ Direct all correspondence to Apoorva Ghosh, Department of Sociology, 3151 Social Science Plaza, University of California, Irvine CA 92697-5100 or email: apoorva.ghosh@gmail.com.
} 


\section{Introduction}

Over recent decades, a range of scholars have studied sexuality as a transnational phenomenon. These scholars have viewed homosexuality or simply sexuality as being constructed through global contacts and cross-national learnings (e.g. Blackwood, 2005; Boellstorff, 2005; Grewal and Kaplan, 2001; Johnson, 1997; Puar, 2001). This “transnationalism” in sexuality may signify that postmodern asymmetries in sexuality have occurred because of globalization, and that these asymmetries may lead to understanding individuals either as “displaced,” and hence transnational, or as innovative and transformational beings in search of new meanings and sexual identities (Grewal and Kaplan, 2001). More specifically, transnationalism challenges local-global binaries in sexuality, viewing it rather as constructed as a simultaneous outcome of localization and globalization. Transnational processes, such as diasporic movements, job flows, the accessing global mass media, and the flow of capital across states and organizations, connect people and cultures all across the world. Importantly, these processes also help lesbians and gay men learn about different sexual cultures and modify their own sexual behaviors in pursuit of a greater coherence between their sexuality and their lives (Blackwood, 2005).

Although current studies have explored transnational sexuality in South-East Asia in relative depth (e.g. Blackwood, 2005; Boellstorff, 2005; Johnson, 1997), South Asia, and especially India, remains somewhat understudied in research on transnational sexuality. Indian/South Asian-based sexuality studies have focused largely on state repressions of sexual minorities in the wave of resurgent (Hindu) nationalism (e.g. Bacchetta, 1999), struggles against anti-sodomy laws (e.g. Narrain and Gupta, 2011), socio-economically marginalized queer communities such as hijras (e.g. Goel, 2016), queer sexualities in rural and semi-urban regions (e.g. Khanna, 2009, 2013), sexuality and Indian cinema (e.g. Khubchandani, 2016) and the uniquely “Indian” forms of sexuality practiced either in India or in its diasporic communities (e.g. Gopinath, 2005; Katyal, 2011). A strand of this latter group of studies has also explored how same-sex relationships and attractions are practiced differently in India compared to the West (e.g. Seabrook, 1998). 
Very few studies, however, examine sexuality in India as a transnational phenomenon. Although communications technologies and transnational mass media continue to rapidly connect India with the rest of the world (Mankekar, 2004; Vanita, 2007), and while several scholars have examined queer movements in India within the framework of global lesbian and gay social movements (e.g. Dave, 2012; Kapur, 2000), very few studies (see e.g. Shahani, 2008) examine how lesbians and gay men in India construct their sexuality under these transnational influences. Specifically, little is known about how lesbians and gay men reconcile competing notions of sexuality that they receive from different sources, such as their own societal and family norms, and those connecting them globally that make them aware of sexuality in other countries and world regions.

This study is based on interviews with professionally employed lesbians and gay men who live in Indian cities and are globally connected by some means, such as through their diasporic experiences, exposures to foreign mass media, or through working in transnational corporations. To explore how lesbians and gay men navigate competing notions of sexuality, this study explicates the mechanisms of interaction between conceptions they receive from their local social norms and those received from their transnational exposures. I employ understandings developed concerning cultural schemas (Sewell, 1992) to explain these intersecting cultural forces, focusing particularly on the transposable and generalizable characteristics of schemas to illuminate the effects of globalization on sexuality. I contend that, although the "pathways" of transnational contacts bring certain schemas of sexuality into an individual's life from elsewhere, these schemas need not necessarily occupy all the spheres of that individual's life; on the contrary, multiple schemas may coexist within different life spheres, resulting in a configuration of schematic cognition that I identify as "differential congruence.”

The transformation of sexual schemas due to transnational contacts and the tensions between competing schemas is understood quite well both in western contexts (e.g. Carrillo, 2018) and in nonwestern ones (e.g. Blackwood, 2005; BoelIstorff, 2005; Johnson, 1997). A lesser-explored phenomenon, however, is that lesbian and gay individuals may choose to adopt multiple sexual schemas in the course of 
their lives, some of which might be received through their transnational contacts. In pursuit of dignity and stability in their lives, these individuals may compartmentalize their sexuality across family, work, and other social spaces. I next present a brief overview of sexuality in India, especially in the urban regions, and use sexual schemas to explain how transnational sexuality might exist in compartmentalized forms in the lives of lesbians and gay men.

\section{Sexuality in Urban India}

Sociological studies often examine sexuality in urban India using a Bourdieusian poststructuralist paradigm (e.g. Bose, 2008; Boyce and Khanna, 2011; Shahani, 2008; Tonini, 2016). This paradigm suggests that the key to understanding sexuality lies in the study of action because people interpret rules differently in terms of their interests and decide when it is convenient to translate those rules into practice (Bourdieu, 1977). As a result, although same-sex identifications such as "gay,” “lesbian,” or "bisexual” may be frowned upon in communities of sexual minorities because of notions of cultural inauthenticity and political expediency (Dave, 2010) or may be dismissed altogether in orthodox heteronormative setups (Khan, 2001), sexuality ought not to be assessed purely on the basis of such norms. Akhil Katyal's idea of “doubleness” in sexuality (2011), for example, vividly explains the bittersweet relationship that gay men in India often establish with their sexuality and sexual identifications. While being members of communities of gay men, they may denounce the practice of being identified as a gay or bisexual man because of the "shame" associated with being so and the "fear" of losing their heterosexual privileges, which are also intricately tied with their male privileges that are the main source of the respect and stable financial and emotional outcomes they derive from their family, workplace, friends, and society in general. To an observer, such tendencies may look like a “double game” that gay men generally play while deploying their sexuality.

The motives behind doubleness can be understood in the light of a "shame culture" in Indian society, which ensures that an individual's reputation is intricately tied to their family's reputation (Vanita 
and Kidwai, 2008:198-9). Therefore, any behavior considered socially deviant committed by an individual (such as teenage pregnancy, single parenthood, or childbirth from an extra-marital relationship) or setbacks experienced in the course of one's life (such as rape or incarceration) often tarnish the reputation of the family the individual is affiliated with. Such deviant events, if they have occurred, are often concealed to shield the family concerned from public ridicule and shame. Same-sex proclivities are not excluded from being a reason for causing shame to an entire family. Same-sex sexuality is too awkward a subject for discussing in public or within the family. The "taken-for-granted" assumption of heterosexuality is often inherent in the "seamless" transition from adolescence to adulthood through the institutions of (opposite-sex) marriage and procreation. This transition can be construed as being integral for entering into mainstream social life or for becoming a social citizen. An individual's refusal to carry out those filial duties becomes a "declaration of difference” to this norm and, therefore, any individual declaring such a difference could face enormous emotional pressures from their family to change their decision.

Using a cultural framework approach helps understand aspects of sexuality in India, including doubleness. Declaring oneself as "gay” or "lesbian” and therefore deciding not to marry a person of the opposite sex can cause serious repercussions for individuals doing so and for their families. Nonetheless, same-sex behaviors may be tolerated despite risks to the familial reputation as long as those actions remain hidden. Similarly, same-sex relationships may also be "tolerated” as long as those relationships are publicly portrayed as nonsexual and do not disrupt family life. However, such relationships, if acknowledged as conjugal or romantic, would be unlikely to receive public or familial support (Vanita and Kidwai, 2008:198-9).

How do lesbians and gay men express same-sex behaviors and relationships under such cultural constraints? A range of sexuality scholars (Eng, 2001; Gopinath, 2005; Manalansan IV, 2003; Massad, 2002; Muñoz, 1999) have noted limitations in the relevance of the Euro-American practice of "coming out” and self-identifications in examining sexuality in the global South, much of which also applies to 
India. They claim that same-sex proclivities in non-western contexts are more complex than those explained by these types of sexual categories and the binaries of being "out or in the closet." Concurring with that view, in the Indian context, Boyce and Khanna (2011) proffer the concept of "moral ambivalence” to explain how same-sex behaviors and relationships may be expressed in urban India. Boyce and Khanna (2011: 89-90) contend that it could be problematic to explain the prevalence of samesex behaviors and relationships in India through notions of sexual liberation that challenge orthodox norms of marriage, family, and kinship. Moral ambivalence means that, within the unbending norms of heteronormative family traditions, lesbians and gay men deploy their sexuality under an implicit toleration of "unscrutinized same-sex sexual contacts" in "homosocial” spaces. Homosocial spaces are socio-cultural spaces within families, schools, social networks, and workplaces that discourage oppositegender intermingling but encourage same-gender socialization. These scholars contend that theoretical frameworks that treat "homosocial" and "homoerotic" as distinct and exclusive categories are unsuited for understanding what occurs in a large part of (urban) India.

More recently, Maria Tonini (2016) added to the discussions on moral ambivalence and doubleness in claiming that it is common to observe multiple forms of negotiations that seek sexual recognition (or non-recognition) in legal institutions, the family, and other social institutions in pursuit of a dignified life. Although the success in decriminalizing sodomy in 2009 paved the way for some lesbians and gay men to confront and assert their sexuality in those institutions, many of them decided to return to a state of obscurity and unrecognition when the decriminalization of sodomy was pronounced void in 2013. However, others refused to go back into their “closets”; they wanted to continue their participation in the struggle to seek another victory. In the process, they swung between ambivalence in their social and family spaces and formal acknowledgement in their activism spaces of their sexual identity. They recognized in their fields of activism that sexual identifications were necessary to make their concerns heard and for globally integrating with struggles on lesbian and gay equality, but in their social and family lives, they scaled down their sexuality to a state of ambivalence, anonymity, or even unrecognition. 
An understanding of multiple negotiations suggests that doubleness and moral ambivalence toward sexuality may not necessarily involve absolute outcomes. Activism and mobilization may alter the ways lesbians and gay men construct their sexuality, but other factors may also be involved. Scholars recognize that transnational influences ought not to be ignored while studying sexuality in India as lesbian and gay social movements in India are known to have been affected by major transnational influences. The success of lesbian activism organized by Giti Thadani over other forms of "culturally authentic" feminist activism in the early 1990s and the use of Swedish funding for litigating the decriminalizing of sodomy in 2009 are two examples of queer activism being transnational in nature (Dave, 2010; 2012:10). However, questions remain as to which routes and mechanisms explain how transnationalism brings structural changes in sexuality, and how preexisting structural forms of sexuality interact with the structures that arrive through those routes and mechanisms.

Post-structuralist paradigms seek to account for cross-cultural variations in sexuality, but their reliance on understanding sexuality through a “complex repertoire of indigenous signifiers” (Adam, 1986: 20, emphasis added) explains little concerning how sexuality might undergo structural changes when encountering forces such as social movements and globalization. Institutional theories, in contrast, facilitate an examination of the transposable and generalizable nature of sexuality and how structurally constructed forms of sexuality are amenable to change under global social forces.

\section{Cultural Schemas and Transnational Sexuality}

Many scholars (e.g. Osella, 2012) caution against suggesting a “teleological” move from traditionalism to Westernization in explaining the diffusion of individualist-centric practices in marriage, the family, and sexuality. Institutional theories (e.g. Dimaggio, 1997; Dunning, 1999; Fiske and Taylor, 1991; Sewell, 1992) account for these concerns through avoiding simplistic generalizations in the processes of cultural diffusion. I operationalize these perspectives in my study by employing cognitive structures called schemas. Schemas comprise the memory traces detailing the "knowledgeability" of 
individuals that can be put into practice or action (Sewell, 1992). Schemas combine Anthony Giddens’ concept of duality of (knowledge of) rules and resources (Giddens, 1976, 1981) and Pierre Bourdieu's concept of habitus (Bourdieu, 1977) to represent cognitive structures that are amenable to change with updated knowledge and resources. Transnational sexuality dovetails with the conceptual framework of schemas in helping to understand better how reproducing social actions and creating change in institutions occurs through exercising human agency. Cultural changes, therefore, may be explained in greater depth when the processes of diffusion are viewed in terms of schematic cognition. Using schemas as cognitive structures, it can be seen that structural patterns may expand or update as individuals exercise their agency and when culture-structures interact with each other.

The schematic cognition view in institutional theory suggests that the metaphors and meanings that constitute structures can be learnt from various sources and that, therefore, new institutional structures are likely to differ from pre-existing ones. These configurational changes are not idiosyncratic; these can be theorized because schemas are both generalizable and transposable, forming a balance between change and continuity. The understanding of "generalizability” here draws on Anthony Giddens' view that schemas can be reproduced in social lives and applied in various contexts of interaction. The term “transposability” derives from Bourdieu’s concept of habitus whereby schemas also draw on past experiences and pre-existing knowledge (Sewell, 1992). Because schemas account for both change and continuity in the process of cultural diffusion, they are likely to serve well as potentially persuasive theoretical tools to explain intersecting structures and their resulting outcomes.

Although the schematic cognition perspective in studying transnational sexuality is not entirely new (cf. Carrillo, 2018), this analytical tool remains underexplored in the sociology of sexualities. Several sexuality studies (e.g. Boellstorff, 2005; Johnson, 1997) suggest the embeddedness of duality and habitus in sexuality and a possible analytic use of schematic cognition. Tom Boellstorff (2005) coined the term “dubbing culture” in which Western discourses on sexuality are transmitted from US television into Indonesia but are dubbed into the local Indonesian language. Therefore, queer Indonesians often identify 
themselves through lesbi and gay subjectivities, written in italics to distinguish them from the original American terms. Subjectivities refer to social categories, in contrast to identities, wherein individuals place themselves in response to their own life course and cultural understandings of sexuality and eroticism. These subjectivities are neither purely Western nor purely Indonesian but represent Indonesian pride in being part of global cultures while remaining authentically Indonesian.

Similarly, Mark Johnson (1997) observes that gay or bantut beauty contests in the southern Philippines exemplify an acceptance of Western sexual identifications in orthodox Muslim regions. Through their beauty, the transgendered "gay" males identify with an ethno-nationalism that aligns with the traditional orders of masculinity and femininity. They represent imageries of “defiled women” and “failed masculinity” that fit within the cultural interpretations of queer sexuality in the southern Philippines. At the same time, through their education, spoken English skills, transnational cosmopolitanism, professionalism, and good citizenship on which they are assessed in those contests, they link themselves with forms of sexuality associated with and globalized by the United States.

These examples show that, while knowledge of rules and resources can be acquired, the presence of pre-existing cognitive structures can result in the formation of compound or hybrid forms of sexuality. In contrast to post-structural paradigms that rely on an interpretation of prevalent norms that reproduce social action (Bourdieu, 1977), the schematic cognition approach accounts for the construction of transnational sexuality through diffused notions of sexuality while also retaining pre-existing cultural understandings of sexuality.

While hybrid cultures, such as those exemplified through the dubbing culture and bantut beauty contests, provide useful frameworks for understanding transnational sexuality, it is important to also understand the constituent sexual schemas involved in examining other configurations that might result from the interactions occurring. 


\section{Competing Sexual Schemas}

Sexual schemas, that is, the cognitive structures of metaphors and meanings assigned to sexuality, may be intricately connected to the national cultures in which they originate. National culture refers to "a set of [shared and widely accepted] norms, behaviors, beliefs, and customs that exist within the population of a sovereign nation” (Lin, 2014: 369). Cultural citizenship, including the performative acts and rituals that individuals allude to, and national identity, uniquely shape notions about sexuality and its identifications (Altman, 2002; Manalansan IV, 2003; Massad, 2002). As a result, sexual schemas are likely to be location-dependent.

Sexual schemas can be multifarious as heterogeneity in societies created by multiple social categories, based on gender, ethnicity and class, ensures that no national culture has one unique sexual schema (Altman, 2002). The identification of sexual schemas for this study is specific to those arising in the interviews analyzed. While multiple sexual schemas may exist within a national culture, the purpose of this study was to help understand how schemas from different national cultures may interact, how those interactions construct sexuality as a transnational phenomenon, and how sexuality might be deployed in the lives of globally connected gay men and lesbians.

\section{Sexual Exuberance as a Sexual Schema}

I conceptualize a schema of “sexual exuberance,” meaning sexuality in its celebratory and assertive form and involving self-identification, as one which draws on the ethos of homonationalism (Puar, 2013). Homonationalism asserts that lesbians and gay men should have an identity, voice, and representation in political and social institutions and considers there to be a positive association between sexuality and nationalism. It highlights a link between the intricate ties of sexual citizenship and a nation’s capacity to exercise sovereignty and protect its people, indicating "a facet of modernity and a historical shift marked by the entrance of homosexual bodies as worthy of protection by nation-states, a 
constitutive and fundamental reorientation of the relationship between the state, capitalism, and sexuality" (Puar, 2013: 37).

In the US, for example, sexuality has powerfully influenced political, economic, and religious institutions, similar to other social categories such as race/ethnicity, gender, and social class, especially since the early 1970s. On the political front, gay and lesbian movements and anti-gay right-wing movements have been leveraging their identity politics to engage in struggles to mobilize electoral constituencies and attempt to move policy decisions in their favor (Bernstein, 2002). In the workplace, lesbians, gay men, and their allies have enjoyed significant success in running campaigns to have sexuality included as a protected category in employment nondiscrimination policies and for having same-sex domestic partners included in employee health insurance programs (Raeburn, 2004). Large business corporations in the Fortune 1000 are now being publicly evaluated on their gay-affirmative attitudes (Briscoe et al., 2014). Sexual identities have also become distinctly visible in religious contexts, with the proliferation of gay-affirmative Christian congregations (Kane, 2013). Schools have begun to recognize the need for "queering” their institutions through creating a "safe space” for young gay persons to self-identify along a spectrum of gender and sexuality (Malmquist et al., 2013). The affiliation of sexuality with political, social, and economic institutions has ensured that sexuality remains visible, contested, and is asserted through categorical identities.

The association of sexual citizenship and national identity in the US as well as in Western Europe has reinforced sexuality, although often as a contested terrain, in the cultural and sociopolitical imaginations of people. Therefore, lesbians and gay men in these regions are far more likely to selfidentify with sexual categories such as "gay man” and "lesbian” and to celebrate their "pride” in their sexuality by walking in pride marches, organizing National Pride days, and expressing their sexuality in multifarious ways that gives them a sense of being visible and unapologetic in being gay (Ferrante, 2014; Hubbard and Wilkinson, 2015; Kehl, 2018). 
When sexual exuberance is pushed into the fore of social life, lesbians and gay men are more likely to self-identify and come out. In many instances, coming out could be simply an act to express sexual authenticity to family, friends, and coworkers to win their trust and support when concealment is either less desired or a less viable option (Corrigan and Matthews, 2003; Legate et al., 2012). Under the schema of sexual exuberance, coming out has been intertwined with queer exceptionalism that undergirds homonationalist discourses and romanticizes sexuality. Lesbians and gay men feel motivated to come out not simply from some form of compulsion or due to concerns relating to authenticity and practicality, but also because they are increasingly driven by the pride and exclusiveness of being gay and can draw on role models of people who have led successful lives while being proud as gay (Puar, 2013). In western countries such as the US, an investment in queerness as a national discourse has led to self-identification and coming out as often being viewed as prerequisites for familial acceptance of gay men and lesbians (Mattison and McWhirter, 1995). In workplaces too, the celebration of National Coming Out Day makes the practice of self-identification and sexual visibility more common and less stigmatized as a result of sexual exuberance (Ghosh, 2012). Hence, although sexual exuberance encourages lesbians and gay men to come out, coming out by itself may not be a signifier of individual sexual exuberance.

\section{Moral Ambivalence as a Sexual Schema}

The sexual schema that this study identifies as emanating from social norms in India is in stark contrast to that of sexual exuberance. Sexual schemas can be both the medium and outcome of social practices (Sewell, 1992). Therefore, moral ambivalence, as shown in the literature review, can also be framed as a sexual schema that lesbians and gay men may use for deploying their sexuality in response to society's ambivalent attitudes toward sexuality. In contrast to sexual exuberance in the US that opens broad possibilities for lesbians and gay men to self-identify and talk about their sexuality, such actions in India could be awkward and even shameful. Because of the shame and ambivalence surrounding sexuality, coming out as gay is likely to seem less plausible in terms of Indian cultural values. Therefore, gay men and lesbians in India are less likely to discuss their sexuality in their social settings, be it in 
family, work, or friendship circles. As noted, this is because an individual's reputation is intricately linked with their family's reputation, and therefore the "shame” of being gay could transfer to their family as well. In families, coming out can be perceived as being disrespectful to elders and shameful for the entire family (Boyce, 2006; Boyce and Khanna, 2011). Indian men, especially, are generally bound to their families even after becoming financially independent. These emotional bonds carry expectations of oldage care, bringing "stability" in life through becoming "settled" in marriage, and procreating to further the familial lineage (Jethwani et al., 2014). If a son, especially an elder or an only son, comes out as gay, this event will generally violate most of the social, economic, and cultural expectations that parents usually have of their son.

When coming out or being open about sexuality is a distant possibility for many gay men and lesbians, they may leverage the "silent toleration" of same-sex behaviors that occurs when those behaviors are not intrusive on their filial and social duties and are practiced as a secondary behavior, like some sort of recreation enjoyed anonymously. While taking this option, they may not self-identify as gay and may engage in same-sex behaviors while complying with heterosexual expectations, for example, by remaining in a heterosexual marriage relationship or planning for a heterosexual marriage (Seabrook, 1998). Although seeking to satisfy same-sex quests for love and love-making is a universal phenomenon, my interviews suggest that lesbians and gay men may expect their significant others (such as parents, siblings, and close friends) to "know" about their sexuality without confronting this matter and, in so doing, enable them to escape from expectations of heterosexual marriage, which makes ambivalence around sexuality even deeper.

In recent years, an increasing visibility of queerness in the Indian media (e.g. Khubchandani, 2016) and legal struggles in relation to anti-sodomy laws may have led to gradually increasing confrontations concerning sexuality in socio-cultural spaces. Such changes, however, are more likely to generate adaptations within current familial and social normativity rather than create a new social normativity (Singh, 2017). In the absence of socially respectable discourses and recognized differences 
concerning sexuality of specifically Indian origin, the norms of heteronomy and traditional filial duties that underpin moral ambivalence concerning sexuality are likely to remain as strong as before (Ghosh, 2015). I discuss this aspect below in relation to the interviews to further clarify how moral ambivalence may exist as a sexual schema in the lives of lesbians and gay men in response to ambivalent societal attitudes regarding sexuality. Unlike social environments that valorize "coming out" and where the onus is on the individual to let their significant others, that is, their family and friends, know about their sexuality through a coming out encounter (Corrigan and Matthews, 2003; Legate et al., 2012; Mohr and Fassinger, 2000), in situations characterized with moral ambivalence, as shown through the interviews in this study, lesbians and gay men may expect their family, friends, and coworkers to "know" about their sexuality after having observed them over time and taking an interest in them. At the same time, they may also expect those significant others to implicitly tolerate their sexuality without creating an awkward need to speak about it.

\section{Interviews}

A duality of structures presupposes the knowledgeability of actors; actors are presumed to have access to both the rules and the resources of structures to allow for schematic cognition (Sewell, 1992). Hence, to examine the interaction of competing schemas of sexuality in this study, I used interviews obtained from respondents living in metropolitan cities, self-identifying as gay, lesbian, or queer, and speaking English with basic fluency, as these individuals were more likely to have access to global connections compared to similar individuals otherwise less well educated and/or living in rural areas and villages.

I conducted interviews between September 2012 and June 2013. The interviews had two aims. The first aim was to capture how the respondents constructed their sexual identifications in terms of being gay, lesbian, bisexual, or queer in their families, workplaces, and social life. In this part of the interview, I asked them about their coming out encounters; if they had had any, and how being part of a sexual 
minority affected their day-to-day life. The second aim was to explore the respondents’ possible participation in lesbian, gay, bisexual, and transgender (LGBT) activism. In that part of the interview, I asked them about the types of strategies LGBT social movement organizations deployed in their activism and the specific roles the respondents played in those organizations. The interviews were semi-structured and open-ended in nature. I recruited the respondents from several LGBT social movement organizations in India and from a dating website for gay men. In all, I recruited 21 respondents, 18 of whom qualified within the scope of this paper in terms of their sexual identifications (the three excluded respondents identified as either heterosexual or bisexual). Of these 18 respondents, 12 were active in LGBT activism and the rest were not. In terms of their locations, 4 respondents were from Bangalore, 2 were from the Delhi-NCR region, 1 was from Hyderabad, 3 were from Kolkata, and 8 were from Mumbai. The respondents also represented a broad age range, with 6 in the 20-29-year age range, 1 in the 30-39-year age range, 7 in the 40-49-year age range, 3 in the 50-59-year age range, and 1 respondent was 75 years old. A total of 11 respondents came from a variety of professions, such as journalism, psychiatry, science/research, media/film-making, human resource management, retail management, marketing, and management teaching, while the remaining 7 were fully engaged in community work or activism for LGBT communities.

In terms of sexual identification, 10 respondents self-identified as gay men, 1 as a queer man, 3 as lesbian women, 3 as queer women, and 1 as a gender queer individual. In India, an identification as “queer” may signify a dissenting stance taken by some homosexual men and women toward a perceived elitist status of "gay" and "lesbian" identities. The elitism attached to these identities is often associated with their Western origins and needing to have English language fluency to claim them, since the latter is a skill that only a minority of gay men and lesbians in India have and is limited primarily to those who live in cities (Narrain and Bhan, 2005). Because of this situation, describing oneself as "queer" often signifies a willingness to challenge class-based differentiation related to the terms "gay" and "lesbian," and the term “queer” is used instead by many working class gay men and lesbians, as well as by other gay 
men and lesbians wishing to express their solidarity across class lines, and does not therefore signify any reticence toward same-sex attraction. Given this context, in a study of gay men and lesbians in India, perspectives from “queer” men and women are likely to be as important as from those who self-identify as "gay” or "lesbian."

In this paper, I identify the respondents using fictitious names for confidentiality purposes. In addition, when discussing specific respondents, I state their age at the time of the interview, gender, selfidentified sexual orientation, profession, and location. I interviewed all the respondents in English, and the original choice of English wording has been retained in quoted text to ensure the respondents' views are conveyed in their own words. Overall, this sample drew from a population of lesbians, gay men, and queer individuals in India who were middle class, professionally active, and who lived in cities.

\section{Transnational Pathways}

All respondents had a compelling story to tell. To explore their stories within the theoretical parameters of this study, and to develop a focused respondent-inclusive approach, I applied a thematic analysis based on “transnational pathways.” Individual experiences embedded in the processes of globalization do not occur in a vacuum. The mediums of cross-cultural contact, such as the experience of living abroad, traveling to foreign countries for work, and global mass-media, play an active role here. A transnational pathway may be understood as a globalization conduit offering access to diverse cultural or sexual schemas when moving between nations. I highlight some illustrative stories from the narratives of my participants to examine how sexual schemas interact with each other. Overall, I examine the role of diasporic experiences, the transnational workplace, and global mass-media as transnational pathways in helping the respondents deploy transnational sexuality in their lives.

\section{Diasporic Experiences}


People with diasporic experiences, meaning experiences gained by living in a foreign country ranging from a few years to an entire lifetime, may come to question their previously accepted cultural beliefs after living in a foreign location. For example, lesbians and gay men may discover new thinking on sexuality, such as sexual freedom and assertions of sexuality, and begin to question previous practices of relegating sexuality to the margins of social life. These discoveries may have a lifetime impact, as happened in one respondent's case. While in his mid-20s, Rahul (48, male, gay, marketing consultant, Mumbai) went to the US to pursue graduate studies. He realized during his stay in the US that same-sex relationships could have social meanings unlike those he had experienced in India which involved "short term flings” or "hook-ups,” meaning casual sexual encounters. He says:

I did my BE [Bachelor of Engineering] and then I also went to the US for higher studies and my $\mathrm{PhD}$ and everything, so I was there for [6 to 7 years]. I couldn't say how my life would have turned out if I had not come to the US at that time because I was actually working in Kolkata with an advertising agency. I was staying alone and I was already seeing a couple of guys and doing hanky-panky [engaging in casual sexual encounters], but I still had no formal plan in terms of what I was going to do. I think it was only when I went to the US that I got major exposure to the gay lifestyle, as it were, in the LGBT groups on campus and so, within a couple of years that was two generations, in a manner of speaking, ahead in terms of knowing a lot about how gay people live and gay relationships and gay romance and stuff like that. (emphasis added)

I expressed my curiosity about the term “gay lifestyle.” He shared his memories of LGBT visibility on his university campus, something that he never encountered before. He said:

It was quite a revolution to see the LGBT [student] groups being quite open on campus...It is not that everybody was out, I think there was still lot of people chose to be in the closet but I also saw lot of people being out... and then I also had never been to a gay club or a gay dance bar or something like that... so there were many, many such aspects where for instance I could realize 
that we could actually have genuine friendship with other gay men... [Genuine friendship means] that you could be only friends without having any romantic or sexual equation [connection] with the person.

For Rahul, a "gay lifestyle” meant being visible in public spaces as gay and networking socially with gay men as a way of asserting sexuality. Rahul spent seven years in the US for his graduate studies and for a short phase of employment. His narrative suggests that diasporic experiences could be a means of diffusing different cultural notions and practices on sexuality. In Rahul's case, I found that his diasporic experience served as a transnational pathway for him that made him knowledgeable about some of the cultural practices on sexuality in a foreign location.

Rahul’s experience suggests that he had entered into a schema of sexual exuberance through his diasporic experience. He was exposed to a culture where non-normative sexuality was celebrated and openly admitted. People shared collective solidarity through self-identifying as "gay" and forming cultural groups in relation to that identity. When Rahul returned to India, this schema occupied his private and non-work social life. He told me that his experiences in the US prompted him to have a male partner in India, whom he called his "boyfriend." At the time of my interview, he was a prominent and visible gay activist in Mumbai and had delivered several talks on LGBT inclusion on university campuses. He also moderated listservs of gay men in India while disclosing his real name and identity. His social media profiles had pictures of him participating in pride marches and LGBT festivals. He told me that he had become active in networking with gay men within a few years of coming back to India.

Although I found a schema of sexual exuberance persisting in Rahul's private and non-work social life, I found little evidence of this schema in his family and work life. He could not fully inform his parents about his boyfriend who had entered his life after coming back from the US. It was comforting for him that he lived "a very un-interfered gay life" in Mumbai with his boyfriend. Rahul's parents lived in Delhi-NCR, approximately 900 miles from Mumbai, and visited him twice a year. Rahul believed that he 
had introduced his boyfriend to his parents in an "indirect sense.” When his parents visited him, his boyfriend only dropped in for dinner and went back to his residence after dinner. For Rahul, this practice and his reticence towards marriage were sufficient indicators for his parents to "know" about his samesex relationship and that he was gay, although he had never sought any confirmation from them to verify his presumptions.

At the time of the interview, Rahul worked as a consultant in the Mumbai location of a UK-based communications and marketing services company. Although he socialized with his gay friends and participated in pride marches, he usually tried to remain discreet about his personal life at work. He tried to avoid questions about his family (i.e., his presumed wife and children) in his business meetings and conferences. His strategy to escape from any attention to his private and social life was to be more inquisitive about the heteronormative family lives of his colleagues. He claimed to be "good at making small talks...and keeping stuff very general.”

Rahul's family and work life seemed to involve a schema of moral ambivalence around his sexuality, whereas his private and social life showed a significant presence of sexual exuberance first received from his diasporic experiences. I define such a configuration of schematic cognition as differential congruence wherein different schemas of sexuality may occupy different spheres of one’s life. I have drawn out a conceptual understanding of Rahul's story as one in which the transnational pathway of diasporic experiences transmitted a schema of sexual exuberance from elsewhere into his private and social life. The presence of moral ambivalence around sexuality in his family and work life suggested that the two schemas of sexuality were separately congruent within the different spheres of his life.

\section{Global Mass Media}

Mass media and communication that broadcast popular artforms, such as music and cinema, can play a prominent role in diffusing foreign notions of sexuality, and it is of interest to examine how these 
transmitted notions are internalized by individuals and what effect these notions have on their lives. Within family and work circles that view sexuality differently, how might these new notions of sexuality occupy a place in one’s life? One respondent, Nishi (26, female, lesbian, sales and retail manager, Kolkata/Delhi-NCR), attempted to address this question. I provide a snapshot of Nishi's life prior to engaging with her response.

Nishi was raised in a suburb of Kolkata where her parents have always lived. She informed me that her mother knew that she was a lesbian. This had happened around one year before her interview with me. She vividly explained how she accidently came "out" to her parents when she suffered a severe breakdown after a failed relationship with a woman that her parents knew as her childhood friend:

When I had a breakup, it was like a dramatic wake up. I [was] admitted in hospital, I was so emotionally broken, so everyone got to know. There was so much frustration. I [don’t] know why I am telling all this, but in my hostel I thought of suicide also, that I should do suicide may be because end of life and all and may be, I will not be able to live again, so I thought of suicide twice then when I went back to home after exam I was crying like anything morning, night, late night, and my parents were like what the hell is happening between two of you and they always [believed] that we are best friends, but it is very unusual for them to take it as, why two girls will be so attached and my [father was] always telling me, see I had a friend also like you, we would live with each other while he was in Kolkata, but we [did] not feel like the way you are behaving —it is completely unnatural, so I could not tell that time. One day morning I told, see[ing] the depression in that level, so I told that I had tried [to commit] suicide, then my mom [came] to know [that] something very serious is going on and they cried, the whole family cried, and that was disaster and all. I thought my [mother] understood, but they were like never ask do not tell policy kind of thing... (emphasis added) 
Nishi never attempted to tell her parents about her relationship when that relationship was current. At that time, her relationship was understood as being under the "hood" of "childhood friendship.” However, after her break-up, her emotional breakdown and her suicidal ideation prompted an involuntary coming out to her parents. The last sentence in the quotation above suggests that Nishi's parents had decided to remain ambivalent about her sexuality after she had come out to them. Was an implicit tolerance also embedded in their response as it was in the case of Rahul's parents? Her later narrative suggests so. Several months after the incident when she had accepted a job in Bangalore and was away from Kolkata, she became upset at one time with her parents when they concealed from her the news of the death of her ex-girlfriend's mother. At that point, she openly discussed her past relationship. She said:

I knew that [my mother] would not understand [these] gay or lesbian terms, so I said [mother,] I love [X-her ex- girlfriend's name], I knew maybe [my mother] also knew what I [was] trying to say, but [she] said I know, then I said no you do not understand, the way you love [my father] and the way [he] loves you, the same way I love [X]. She was silent for quite sometime, then she said it is okay, it is already gone, so no point of discussing it, I [asked if she was] angry on me and she said no I am not angry on you it is okay, you just need to get out of it and she understood I guess somehow and now when I [talk] to her she is like, I accept you, but in future may be, if [you will have] any girlfriend,... you can have your life outside. We love you always, but do not expect us to accept your [sexuality]. I said okay, [I will follow a] do not ask do not tell policy, so they will [be]safe [and] I will [be] safe... few times she also expect[ed] [that] may be some day I will get some guy... she [had those] things on mind. (emphasis added)

Nishi's recalling of this event reveals that she made an agreement with her mother not to discuss her sexuality again with her family. Nishi’s mother understood her daughter’s pain and, possibly, also empathized with her daughter's feelings of being in love but not with the object choice of those desires. Alongside hopes that her daughter might change the object choice of her desires someday, Nishi's mother 
insisted that Nishi conduct her same-sex relationships away from the purview of her familial life. This encounter clearly pushed Nishi’s sexuality further into an ambivalent state involving implicit toleration but with little acceptance.

How was Nishi’s personal life? At the time of interview, she was living and working in DelhiNCR, more than 900 miles away from Kolkata where her parents lived and was still recovering from the trauma of her failed relationship. She had also suffered from discrimination at work due to her nonconforming gender expression. She had a history of changing jobs frequently, and I happened to interview her on a weekend after she had left her job in Delhi-NCR and was about to go back to Kolkata to reunite with her parents. She began to explain to me how she also sought to become stronger during her phases of unemployment. I tried to probe more in that direction. Before I had even finished my question, Nishi interjected, and her interjection suggested how the transnational pathway of global mass media had boosted her morale. Here is our conversation:

Author: Yeah, so you were telling about this phase of being unemployed [that] made you strong and it also made you strong toward coming to your sexuality and...

Nishi: Maybe you will find it is funny but my unemployment phase was still on and you will find it funny, that time I was listening to Lady Gaga all the time and the kind of thinking [...] she frames from her music that made me really strong, today if I am telling anyone without shaking my voice that I am gay may be the influence of her music only... I had my breakup just few months ago and I was going through a terrible time, no job, sexuality problem, could not come out to anybody, that time I started listening to Lady Gaga songs, Poker Face, Bad Romance. Then Bad Romance is one of the songs still make me [feel] somewhere I am weak and The Edge of Glory, Born this Way. Born this Way [is her most influential] song, because of that song I think Gaga got Grammy Awards also- the most influential song of the century...I started [maintaining] [a] page in Facebook also, [with] the name of Lady Gaga from India and the kind 
of thinking and modality she is having. Because when she was not famous she was singing at the gay bar and her first audiences were gay people, she got popularity from the gay people, gay people first recognized her music. So Born this Way song and Edge of Glory, this kind of songs to be beautiful and be what you are. She [is] also openly bisexual, she admits herself [as] bisexual. She now dates a guy, but that is okay she admits herself bisexual, that kind of strength and honesty very few people can have. She is truly [an] artist. So, I got so much influenced from her. If today I am saying that what I am to accept me or do not accept me it is absolutely up to you because of her influence I guess. (emphasis added)

The above quotation is insightful, rich, and powerful in explaining how Lady Gaga's celebration of sexuality through her music reached Nishi through the transnational pathway of global mass media. Nishi's story exemplifies the power of this pathway that she could access, despite the great distances between the US and India, to be inspired with a schema of sexual exuberance.

Although Nishi asserted her sexuality in the interview and vividly described the role of global mass media in making herself strong and confident, this assertion concerning her strength and confidence did not translate to her family life where she was unable to have an open conversation with her father about her sexuality and confined her sexuality to an ambiguous acceptance by her mother. Nishi's story suggests that her family life was congruent with a schema of moral ambivalence but her private life involved a schema of sexual exuberance that, when taken together, resulted in a configuration of differential congruence in which these contrasting sexual schemas coexisted in her life.

\section{The Transnational Workplace}

Manoj (43, male, gay, airlines staff, Delhi-NCR) works in a German multinational airline company that operates in several locations, including India. As I began my interview exploring whether he was open about his sexuality, he told me that, in his early 20s, he had concealed his same-sex 
attractions and usually pretended to be a heterosexual man. During the course of his employment in the airline company as a crew member, he had received numerous opportunities to travel to international locations mostly in Western Europe. He realized through his travelling experiences that in many societies people could openly claim to be gay. He said:

Due to this job of mine I got to travel a lot to Europe. And I got to see in countries like Germany, France, England, there homosexuality was a lot more open. It was lot more accepted than it is in India. I'm talking about late 90s you know, so about 14,15 years back. And seeing there I mean, and seeing how normally we were accepted over there... And you know, they could have a completely non-stressed life... Led me to also get a little more confidence in myself that yeah, there's nothing wrong with me and I can live an open life. So there were--this was actually a huge factor in me deciding to say, "Okay, I'm going to come out now."... And having seen that how open gay life [could be] for them, coming to accept myself was a large part about when I was [travelling] to Europe. (emphasis added)

Prior to this account, Manoj told me that, when he started his employment in the airline company, he had been closeted, and, during his hiring process, he did not care to inquire whether his prospective employer followed any sexual orientation nondiscrimination policy at work. He felt that he was simply "lucky" enough to be "landing" in a company that was gay-inclusive. He also felt that his life as a gay man would have been different if he had worked for another company that did not give him transnational exposure like the one his current employer gave. His overseas travel and exposure to foreign cultures had made him confident to come out as a gay man.

Manoj’s experience suggests a third transnational pathway: the transnational workplace. Working in organizations that operate in multiple countries creates ample opportunities to learn about other national cultures. Ideas concerning sexual liberation are likely to intrigue people such as Manoj who feel 
sexually attracted to people from the same sex but who are normally afraid to accept this orientation because of the negative attitudes toward homosexuality they perceive in their own social settings.

After accepting himself as a gay man, Manoj's attempt to “come out” at his workplace was deliberate. He recounted:

So I think basically coming out to my colleagues was, one day I just told them that I wanted to see all of them. I remember they were all sitting together. We were having a drink in the evening after work. And I told them to come over; I’ll [tell] you something really important. And I told them [that I was gay]. And that will do it, you know, and then I think like most places in the world, I don't think any place would be different, doesn't matter where you work-If you tell two or three people, it spreads to the entire organization. So, I didn't have to go--I didn't have to go and tell each one individually, it just got spread on its own completely you know, within a matter of few days, everybody knew it.

While I found a schema of sexual exuberance to be congruent with Nishi's personal life and with Rahul's non-work social life, in Manoj's case I found this schema to be congruent with his work life. In Manoj's case, his transnational workplace was the pathway that transmitted a schema of sexual exuberance to him.

Was sexual exuberance transmitted to all spheres in Manoj's life? The later part of Manoj’s narrative revealed that, despite having international exposure and internalizing his gay identity, moral ambivalence surrounding his sexuality was a significant factor in his family life. In our conversation on how open he was about his sexuality to his immediate family, he was sure, as Rahul had been, that his parents “knew” about his sexuality without ever having to confront it openly. His parents’ implicit tolerance of his sexuality was broadly suggested in his personal life that remained expressly un-interfered with by his parents and siblings. Manoj's story suggests that sexual exuberance was congruent with his 
work life whereas moral ambivalence explained his sexuality in his family life. Hence, it appeared that his sexuality could also be understood in terms of a configuration of differential congruence.

\section{Other transnational pathways}

In addition to the three pathways described, numerous other transnational pathways may also transmit sexual schemas, which can be briefly indicated in the following examples.

Transnational Ancestry. One respondent, Gilbert, (59, male, queer, fashion designer and LGBT activist, Bangalore) believed that his Anglo-Indian ancestry had helped him in being open about his sexuality in his family. During his adolescence, unlike the other respondents, he felt more comfortable disclosing his same-sex proclivities to his mother. According to Gilbert, his partial English ancestry, and its arguably "progressive” outlook on sexuality, made his mother more tolerant of diverse sexualities and less aligned with orthodox norms on family and marriage. His social life in a non-anglicized neighborhood seemed to be intertwined with moral ambivalence around his sexuality however. Gilbert's neighborhood generated ambivalent attitudes toward sexuality in that it caused awkward moments for his mother (and probably him too) in answering questions about him getting married and raising a family that other respondents also had to face.

International Academia. The situation of another respondent, Abhishek (38, male, gay, sales \& marketing manager/ LGBT activist, Mumbai), suggested that his social life was influenced by "family of choice” ideas derived from his exposure to scholarly studies in sexuality mostly from Europe. Influenced by queer understandings of family, he believed that a family need not be necessarily raised through processes involving procreation or marriage. He believed that he could create his own "family of choice" with people in the LGBT and queer (LGBTQ) community that he was part of. He felt that this avenue gave him the opportunity to go against heteronormative family norms. His work life, on the other hand, was marked with a similar ambivalence around sexuality that I had identified in speaking with Rahul. 
Transnational Activism. Tanvi’s (48, female, lesbian, scientist/ LGBT activist, Kolkata) family life involved a moral ambivalence around her sexuality, similar to that revealed in Nishi’s family life. Tanvi introduced her partner Priyanka (49, female, lesbian, LGBT activist, Kolkata) as "a very close friend" to her mother, siblings, and extended kin. To them, she justified her cohabitation with her "friend" as a necessity for a "single" woman who was unsuited for traditional marriage due to her individualism, feminist activism, and gender nonconformity. In her social life, the pathway of transnational LGBT activism had motivated her to identify as a lesbian to fit into the global LGBT movement. She actively sought international funding for her organization’s feminist and LGBT activism in India and enthusiastically represented Indian lesbians at conferences in Indian and foreign locations.

\section{Discussion}

I found that a schematic configuration of differential congruence may operate because of the coexistence of competing sexual schemas, such as moral ambivalence and sexual exuberance, in one’s life. The transnational pathways discussed in this paper transmitted sexual schemas from different cultures and resulted in schematic configurations, with duality and habitus as two faces of the same coin. Consistent with the institutional theory that I discussed in my theoretical review, transnational pathways made the duality of rules and resources on sexuality accessible to the respondents through generating enthusiasm for a schema of sexual exuberance in some spheres of their lives. The resilience of a schema of moral ambivalence, derived from local social and cultural practices operating in other spheres of the respondents' lives (mainly in the family), exemplified the Bourdieusian notions of habitus and continuity. Hence, consistent with the theory of cultural schemas, a schematic configuration of differential congruence allows for a combination of continuity and change.

Transnational pathways serve as important anchor points for creating differential congruence. In figure 1, I graphically illustrate differential congruence through the coexistence of competing schemas in different spheres of the respondents' lives. The figure shows that a pre-existing schema of moral 
ambivalence pervaded the family lives of the respondents, whereas a schema of sexual exuberance operated largely within their social (work/ non-work) and private lives.

The pathways and configurations I deduced from my interviews are illustrative. My emphasis was on identifying a structured representation of mechanisms that enable schemas to be transferred along transnational pathways, intersect with pre-existing schemas, and produce differential effects. Although my illustrations highlight three transnational pathways in greater detail, figure 1 suggests the possibility of building this matrix further, with more pathways able to be added, as indicated in gray. This extension covers the pathways that I described briefly, and the arrows indicate the possibility of extending this matrix further to include other possible pathways and sexual schemas.

\section{Altering moral ambivalence in the family}

The schemes of differential congruence in figure 1 show that the sexual schemas transmitted through transnational pathways seem generally unable to transform the family lives of lesbians and gay

men. Past studies also indicate that the institution of the family and its arrangements in India are generally less affected by the forces of globalization, such as those arriving through the channels of media and entertainment (Derné, 2005). However, this evidence should not be considered as conclusive. The case of Gilbert (59, male, queer, fashion designer and LGBT activist, Bangalore) suggests that gay and lesbian people could be accepted more in non-traditional families. Although Gilbert attributes the absence of any ambivalence around his sexuality in his family to his "progressive” Anglo-Indian ancestry, I believe that his upbringing by a single mother needs considering. Drawing on studies that highlight gay inclusiveness in non-traditional families (e.g. Lamb, 1998), I believe that the rise of individualism and single-parent families in urban India may be a precursor to greater openness toward varying forms of sexuality in families. 
Figure 1: The Schematic Configuration of Differential Congruence

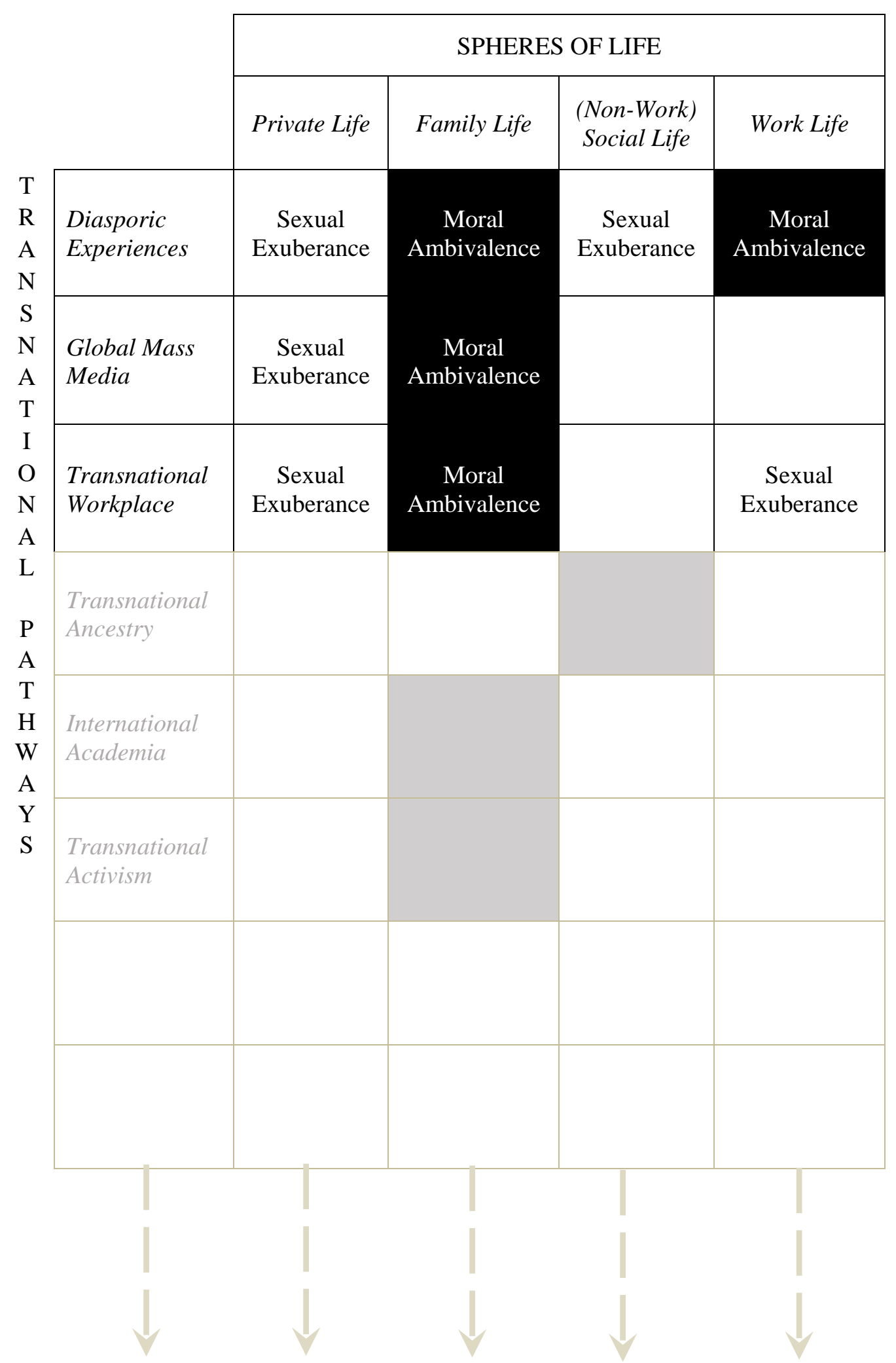


The interview data also hints that transnational families could be a pathway for altering moral ambivalence in family life. One interview participant, Rohit (54, male, gay, filmmaker and LGBT activist, Mumbai), has an elderly sister who has lived in Texas since the 1970s. Rohit described his sister as a gayinclusive person, who cohabited with a "gay buddy." When the sister and her partner visited Mumbai, the three of them and Rohit's partner often socialized together. If one were to consider this group as Rohit's family, it might be possible to view Rohit's family life as exhibiting sexual exuberance. However, Rohit referred to his parents, his other siblings, and their children more often as his family and with whom he was not very open about his sexuality and his same-sex relationship. It is not clear from Rohit's narrative whether there was a relationship between his sister from Texas and the rest of his family. Nonetheless, Rohit's case does suggest that one cannot completely rule out the possibility of transnational families altering the schema of moral ambivalence in the family life of a lesbian or gay man. Future studies examining families that spread out in two or more countries or the effects of having diasporic kin to explore how transnationalism in families works might promote further understanding of how varying forms of sexuality and schemas affect family lives.

\section{Concluding thoughts: Scope for studying sexuality in India}

This study investigated a sample of gay men and lesbians in India who were professionally employed, lived in cities, and who were willing to be interviewed for a research study under confidentiality clauses. Although it is impossible to know whether lesbians and gay men who did not agree to be interviewed would have had similar experiences, I consider it likely that the cultural nuance of differential congruence would apply to other lesbians and gay men sharing the general characteristics of those targeted in this study. I believe that the participation of the respondents in this study shows their grit, courage, and optimism for change. A marker of social change was recently exemplified by the September 6, 2018 order from the Supreme Court of India that decriminalized homosexuality. It was a change that lesbians, gay men, and their allies in India and abroad had been struggling to achieve for several decades. 
Countering assumptions concerning the inaccessibility of gay and lesbian participants in India for research (e.g. Parekh, 2006), this study offers contributions alongside numerous studies (e.g. Horton, 2018; Katyal, 2011; Narrain and Bhan, 2005; Narrain and Gupta, 2011; Shahani, 2008) that have examined middle class lesbians and gay men living in urban India. This study specifically and exclusively examined the transnational nature of sexuality found in this population, including individuals with little involvement in lesbian and gay social movements. The potential for studying the sexuality of professionally employed lesbian and gay men in India is enormous, as this population has either been misunderstood through critical perspectives as "consumption-oriented queers that play by the rules of the neoliberal economy” (Tellis, 2012) or has been less well represented in sexuality studies that have focused more on socio-economically marginalized sexual communities such as Hijras and Khwaja Sarais (e.g. Goel, 2016; Nisar, 2018). The middle class in India is demographically young and aspires to participate in the global economy. Therefore, economic institutions such as the large for-profit business corporations that are increasingly becoming inclusive for lesbians and gay men in their workforce (Ghosh, 2012) may want to understand this internationally minded group more to harness its talent. Research that facilitates this understanding is likely to lead to positive economic and social outcomes.

\section{References}

Adam BD (1986) Age, Structure, and Sexuality: Reflections on the Anthropological Evidence on Homosexual Relations. Journal of Homosexuality 11(3-4): 19-33.

Altman D (2002) Global Sex. University of Chicago Press.

Bacchetta P (1999) When the (Hindu) nation exiles its queers. Social Text 61: 141-166.

Bernstein M (2002) Identities and politics: Toward a historical understanding of the lesbian and gay movement. Social Science History 26(3): 531-581.

Blackwood E (2005) Transnational sexualities in one place: Indonesian readings. Gender \& Society 19(2): 221-242.

Boellstorff T (2005) The Gay Archipelago: Sexuality and nation in Indonesia. Princeton University Press.

Bose B (2008) Modernity, globality, sexuality, and the city: A reading of Indian cinema. The Global South 2(1): 35-58. 
Briscoe F, Chin M K and Hambrick DC (2014) CEO ideology as an element of the corporate opportunity structure for social activists. Academy of Management Journal 57(6): 1786-1809.

Bourdieu P (1977) Outline of a Theory of Practice. Cambridge university press.

Boyce P and Khanna A (2011) Rights and representations: querying the male-to-male sexual subject in India. Culture, Health \& Sexuality 13(1): 89-100.

Boyce P (2006) Moral ambivalence and irregular practices: contextualizing male- to-male sexualities in Calcutta/India. Feminist Review 83: 79-98.

Carrillo H (2018) Pathways of desire: The sexual migration of Mexican gay men. University of Chicago Press.

Corrigan P and Matthews A (2003) Stigma and disclosure: Implications for coming out of the closet. Journal of Mental Health 12(3): 235-248.

Dave NN (2010) To Render Real the Imagined: An Ethnographic History of Lesbian Community in India. Signs: Journal of Women in Culture \& Society 35(3): 595-619.

Dave NN (2012) Queer activism in India: A story in the anthropology of ethics. Duke University Press.

Derné S (2005) The (limited) effect of cultural globalization in India: implications for culture theory. Poetics 33(1): 33-47.

DiMaggio P (1997) Culture and cognition. Annual Review of Sociology: 263-287.

Dunning D (1999) A newer look: Motivated social cognition and the schematic representation of social concepts. Psychological Inquiry 10(1): 1-11.

Eng, DL (2001) Racial Castration: Managing Masculinity in Asian America. Durham: Duke University Press.

Ferrante AA (2014) Homo Skin, Hetero Masks. A Representation of Italian Homonationalism. LES Online 6(1): 114-21.

Fiske ST and Taylor SE (1991) Social cognition (2nd ed.). New York: McGraw-Hill.

Ghosh A (2012) Leveraging sexual orientation workforce diversity through identity deployment. In: Scott C and Byrd M (eds) Handbook of Research on Workforce Diversity in a Global Society: Technologies and Concepts. IGI Global, pp. 403-424.

Ghosh A (2015) LGBTQ Activist Organizations as 'Respectably Queer’ in India: Contesting a Western View. Gender, Work \& Organization 22(1): 51-66.

Giddens A (1976) New Rules of Sociological Method: A Positive Critique of Interpretive Sociologies. London: Hutchinson. 
Giddens A (1981) A Contemporary Critique of Historical Materialism. Volume 1: Power, Property and the State. London: Macmillan

Gopinath G (2005) Impossible desires: Queer diasporas and South Asian public cultures. Duke University Press.

Goel I (2016) Hijra communities of Delhi." Sexualities 19 (5-6): 535-546.

Grewal I and Kaplan C (2001) Global identities: Theorizing transnational studies of sexuality. GLQ: A Journal of Lesbian and Gay Studies 7(4): 663-679.

Horton BA (2018) What's so ‘queer' about coming out? Silent queers and theorizing kinship agonistically in Mumbai. Sexualities 21(7): 1059-1074.

Hubbard P and Wilkinson E (2015) Welcoming the world? Hospitality, homonationalism, and the London 2012 Olympics. Antipode 47(3): 598-615.

Jethwani KS, Mishra SV, Jethwani PS and Sawant NS (2014) Surveying Indian gay men for coping skills and HIV testing patterns using the internet. Journal of Postgraduate Medicine 60(2):130.

Johnson M (1997) Beauty and power: Transgendering and cultural transformation in the Southern Philippines. Bloomsbury Academic.

Kane MD (2013) LGBT religious activism: Predicting state variations in the number of Metropolitan Community churches, 1974-2000." Sociological Forum. 28(1):135-158.

Kapur R (2000) Too hot to handle. Feminist Review 64: 53.

Katyal A (2011) Playing a double game: idioms of same sex desire in India. PhD Dissertation, SOAS, University of London.

Kehl K (2018) 'In Sweden, girls are allowed to kiss girls, and boys are allowed to kiss boys': Pride Järva and the inclusion of the 'LGBT other' in Swedish nationalist discourses. Sexualities 21(4): 674-691.

Khan S (2001) Culture, Sexualities, and Identities: Men Who Have Sex with Men in India. Journal of Homosexuality 40(3/4): 99.

Khanna A (2009) Taming of the shrewd meyeli chhele: A political economy of development's sexual subject. Development 52(1): 43-51.

Khanna A (2013) Three hundred and seventy seven ways of being -- Sexualness of the citizen in India. Journal of Historical Sociology 26(1): 120-142.

Khubchandani K (2016) Snakes on the dance floor: Bollywood, gesture, and gender. The Velvet Light Trap 77: 69-85.

Lamb ME (ed) (1998) Parenting and child development in nontraditional families. Psychology Press. 
Legate N, Ryan RM and Weinstein N (2012) Is coming out always a "good thing”? Exploring the relations of autonomy support, outness, and wellness for lesbian, gay, and bisexual individuals. Social Psychological and Personality Science 3(2): 145-152.

Lin H-C (2014) An investigation of the effects of cultural differences on physicians' perceptions of information technology acceptance as they relate to knowledge management systems. Computers in Human Behavior 38: 368-380.

Malmquist A, Gustavson M and Schmitt I (2013) Queering School, queers in school: An introduction. Confero: Essays on Education, Philosophy and Politics 1(2): 5-15.

Mankekar P (2004) Dangerous Desires: Television and Erotics in Late Twentieth-Century India. Journal of Asian Studies 63(2): 403-431.

Manalansan IV MF (2003) Global Divas: Filipino Gay Men in New York City. Durham: Duke University Press.

Mattison AM and McWhirter DP (1995) Lesbians, Gay Men, and their Families: Some Therapeutic Issues. Psychiatric Clinics of North America 18(1): 123-137.

Massad J (2002) Re-orienting desire: the gay international and the Arab world. Public Culture 14: 36185.

Mohr J and Fassinger R (2000) Measuring dimensions of lesbian and gay male experience. Measurement and evaluation in counseling and development 33(2): 66-90.

Muñoz JE (1999) Disidentifications: Queers of Color and the Performance of Politics. Minneapolis: University of Minnesota Press.

Narrain A and Bhan G (2005) Because I have a Voice: Queer Politics in India Delhi: Yoda Press.

Narrain A and Gupta A (2011) Law like love: Queer perspectives on law. New Delhi: Yoda Press.

Nisar MA (2018) (Un) Becoming a Man: Legal Consciousness of the Third Gender Category in Pakistan. Gender \& Society 32(1): 59-81.

Osella C (2012) Desires under reform: Contemporary reconfigurations of family, marriage, love and gendering in a transnational south Indian matrilineal Muslim community. Culture and Religion 13(2): 241-264.

Parekh S (2006) Researching LGB Youths in India: Still a Distant Dream. Journal of Gay \& Lesbian Issues in Education 3(2/3): 147-150.

Puar JK (2001) Global circuits: Transnational sexualities and Trinidad. Signs: Journal of Women in Culture and Society 26(4): 1039-1065.

Puar JK (2013) Rethinking homonationalism. International Journal of Middle East Studies 45(2): 336339. 
Raeburn NC (2004) Changing corporate America from inside out: Lesbian and gay workplace rights. University of Minnesota Press.

Seabrook J (1998) Men Who Have Sex with Men in India: A Research Note. Millennium 27(4): 10231030.

Sewell Jr WH (1992) A theory of structure: Duality, agency, and transformation. American Journal of Sociology 98(1): 1-29.

Shahani P (2008) Gay Bombay: globalization, love and (be) longing in contemporary India. New Delhi: Sage Publications.

Singh P (2017) At home with their queerness: same-sex relationality and the Indian family in advertising media. Feminist Media Studies 17(5): 721-736.

Tellis A (2012) Disrupting the dinner table: re-thinking the 'queer movement' in contemporary India. Jindal Global Law Review 4(1): 142-56.

Tonini M (2016) The Ambiguities of Recognition. Young Queer Sexualities in Contemporary India. PhD Dissertation, Lund University.

Vanita R (2007) Lesbian Studies and Activism in India. Journal of Lesbian Studies 11(3/4): 245-253.

Vanita R and Kidwai S (eds) (2008) Same-Sex Love in India: A Literary History. Penguin Books. 